\title{
A Study of the Effective and Total Root Surface Area of Extracted Mandibular Human Teeth
}

Juan R. Emmanuelli

Loyola University Chicago

Follow this and additional works at: https://ecommons.luc.edu/luc_theses

Part of the Medicine and Health Sciences Commons

\section{Recommended Citation}

Emmanuelli, Juan R., "A Study of the Effective and Total Root Surface Area of Extracted Mandibular Human Teeth" (1967). Master's Theses. 2084.

https://ecommons.luc.edu/luc_theses/2084

This Thesis is brought to you for free and open access by the Theses and Dissertations at Loyola eCommons. It has been accepted for inclusion in Master's Theses by an authorized administrator of Loyola eCommons. For more information, please contact ecommons@luc.edu. (c) (i) $(9)$

This work is licensed under a Creative Commons Attribution-Noncommercial-No Derivative Works 3.0 License. Copyright $\odot 1967$ Juan R. Emmanuelli 
A STUDY OF THE EFFECTIVE AND TOTAL ROOT SURFACE AREA OF EXTRACTED MANDIBULAR HUMAN TEETH

by

Juan R. Emmanuelli; Jr.

A Thesis Submitted to the Faculty of the Graduate School of Loyola University in Partial Fulfillment of the Requirements for the Degree of

Master of Science

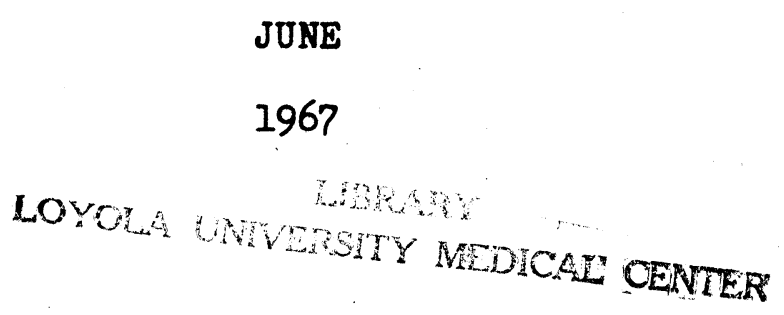




\section{LIPE}

Juan R. Emmanuelli, Jr. was born in Ponce, Puerto Rico, April 2, 1940. He considers himself to be from Peñuelas, a small town in the southern part of the 1sland, where he has lived most of his life. He was graduated from Cologio Ponceño in Ponce, Puerto Rico after completing his high school. He began his pre-dental studies at the Catholic University of Puerto Rico, Ponce, in 1956.

He entered the School of Dentistry, University of Puerto Rico in 1959 and received the Degree of Doctor in Medical Dentistry in May, 1963.

He entered the U. S. Army in September, 1963, and served in Korea and Fort Dix, New Jersey. In July 5, 1965 he began his graduate studies in the department of Oral Biology at Loyola University, Chicago. 


\section{ACKNOWL EDGEMIENTS}

I wish to express my most sincere appreciation to all those who have contributed to the making of this thesis, particularly

To Vincent J. Sawinski, B. S., M. A., Ph.D., my thesis advisor, for his immeasurable guidance in preparing this thesis.

To Joseph R. Jarabak, D.D.S., M.S., Ph.D., Professor in Orthodontics, Loyola University, for inspiring and guiding the investigation for this thesis.

To Douglas C. Bowman, B.S., B.Ed., M.S., Ph.D., my advisor, for his personal interest and ideas in this thesis.

To Clifton V. Moromisato, D.D.S., my classmate and thesis partner, without whose assistance this investigation would have been more difficult.

To Madeleine, my wife, for her understanding, patience and assistance in preparing this thesis. 
TABLE OF CONTENTS

Chapter

Page

I. INTRODUCTION AND STATEMENT OF THE PROELEM • • • • • • -1

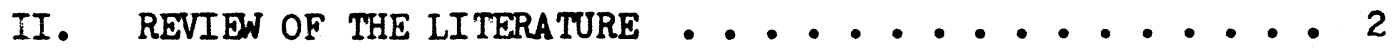

III. METHODS AND MATERTALS

A. Selection of Sample of Teeth . . . . . . . . 5

B. Selection of Membrane Materials . . . . . . . . 5

C. Procedure .. . . . . . . . . . . . . . 6

D. Standarization of Technique and

Testing Precision of Procedure. . . . . . . . 12

IV. FINDINGS

A. Resume of Findings. - . . - . . . . . . . 18

B. Compilation of Data and

Statistical Analysis. . . . . . . . . . . 20

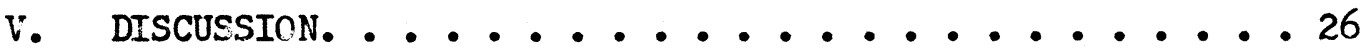

VI. SUMMARY AND CONCLUSIONS

A. Summary . . . . . . . . . . . . . . . 31

B. Conclusions . . . . . . . . . . . . . 32

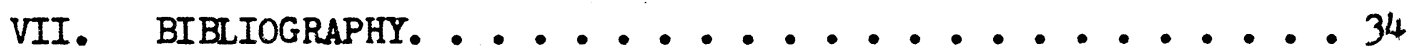


LIST OF FIGURES

Figure

Page

1. TOOTH COATED WITH FORMVAR MEMBRANE

AND REFERENCE PLATE . . . . . . . . . . . 7

2. Membrane halF PEeled aWaY ........... 8

3. FLATTENED MEMBRANE AND REFERENCE PLATE. • • • • • . 9

4. PHOTOGRAPHIC SET UP .............. 10

5. COMPENSATIMG POLAR PLANIMETER . . . . . . . . . II

6. MESIO-DISTAL PROJECTED ROOT SURFACE AREA

OF MANDIBULAR FIRST PREMULAR. . . . . . . . . . 13

7. BUCCO-LINGUAL PROJECTED ROOT SURFACE AREA

OF MANDIBULAR FIRST PREMOLAR. . . . . . . . . 14

8. MESIO-DISTAL PROJECTED ROOT SURFACE AREA AND THE

SECTIONING OF MESIAL AND DISTAL ROOTS OF A MANDIBULAR FIRST PERMANENT MOLAR . . . . . . . . . 15

9. PROJECTED ROOT SURFACE AREAS OF THE MESIAL AND DISTAL ROOT OF A MANDIBULAR FIRST PERMANENT MOLAR. . . . • 15

10. CYLINDER USED TO TEST PRECISION OF PROCEDURE. . . . . 16 


\section{LIST OF TABLES}

Table

Page

I. VALUES FOR CENTRAL INCISORS. . . . . . . . 20

II. VALUES FOR LATERAL INCISORS. . . . . . .... 2 I

III. VALUES FOR CANINES INCISORS. . . . . . . . . 22

IV. VALUES FOR FIRST PREYOLARS ........... 23

V. VALUES FOR SECOND PREMOLARS. ......... 24

VI. VALUES FOR FIRST MOLARS. . . . . . . . . 25

VII. PROJECTED ROOT SURFACE AREAS . . . . . . . . . 29

VII. TOTAL ROOT SURFACE AREAS .......... 30

IX. RATIOS BETWEEN PROJECTED AND TOTAL ROOT SURFACE AREAS . . . . . . . . . 30

X. RATIOS BETWEEN TOTAL AND BUCCO-LINGUAL ROOT SURFACE AREAS ................ 32 


\section{CHAPTER I}

INTRODUCTION AND STATEMENT OF THE PROBLEM

The teeth have roots of different lengths and morphologic configurations; the surface of each root differs.

When the same force is applied to the crowns of teeth in two identical situations, the tooth with the highest root surface area will exert less pressure against the wall of its alveolus through the periodontal ligament.

This experiment is directed toward the determination of the effective root surface area of each tooth as well as its total root surface area.

Effective root surface area is defined as the projected root surface area of the root of the tooth on the pressure side, (Jarabak and Fizzell, 1963).

Projected (effective) root surface area is a two dimensional entity. The term total root surface area is three dimensional because of the convexities of root surface area in the horizontal as well as the vertical planes. It is possible that a ratio can be established between the two after standard values are determined for both. 


\section{CHAPTER II}

REVIEW OF THE LITERATURE

Hanau, in 1919, defined projected root surface area as that area in which the resisting pressure is uniformly distributed in the direction of the morement.

In 1951, Renfroe suggested that in tooth movement only a portion of the root surface area is involved at any one time in resisting the movement of the tooth in the direction of the force. He referred to the effective root surface area when he wrote

"The tooth with a purely round root when moved bodily, presents $50 \%$ of its periodontal ligament fibers to resist the movement and relaxes about the same number. The tooth with a triangular cross section presents a flat surface against the direction it was intended to resist and provides at least two thirds of its periodontal ligament fibers to increase the resistance; the oblong rooted tooth presents flat surfaces to the direction of resistance and almost knife edges in the direction where the resistance is not needed."

Storey and Smith mentioned in 1952

"Undoubtedly it is not the force that is exerted on the tooth that is significant, but rather the pressure (i.e., force/unit area) which is exerted at the interphase of the teeth, periodontal ligament and bone. 
It is the pressure and its distribution over the surface of the root that will be difficult to estimate for various appliances and this could limit their proper design."

They were the first to perceive the important concept of tooth movement being a function of pressure in the physical sense rather than simply a function of force, as well as the relationship present between pressure and root surface area of teeth.

Boyd measured the total root surface area of eighty extracted teeth by using the membrane technique. The procedure was not discussed. In 1960, Tylman gave values for the periodontal area in the entire dentition and compared this to masticatory pressure. The values obtained and the number of teeth measured were not stated.

Jarabak and Fizzell (1963) employed a mathematical model as an adjunct in their description of the biophysics of the orthodontic forces. A parabola was used to represent the contour of the root in their description of translation of the tooth.

It was possible to solve for the centroid on the area with this knowledge. The concept of effective root surface area was developed by means of this mathematical model.

MacEwan in 1954 calculated the total root surface area of the mandibular teeth. These values are inaccurate because the root surface areas were roughly estimated rather than accurately measured. Jepsen, (1963) measured total roat surface area of 238 extracted 
teeth coating the roots with a solution of polyvinyl chloride, dibutyl phthalate, and ech rot (dye). The coating of the root was peeled away, flattened, and the area found by the use of a compensating planimeter. He measured projected root surface, but gave neither the values nor the method employed.

In 1965, Freeman measured the total root surface area, root length and cross sectional area (projected root surface area) of 330 extracted teeth. The total root surface area was measured by coating the roots of the teeth with an air curing latex and using a compensating polar planimeter.

The only values given for projected root surface area were for the first molar and second premolar. All the values obtained in this work, except for the root length of the teeth, were extremely low and when compared to other investigators seemingly incorrect. 
CHUPTER III

METHODS AND MATERIALS

A. Selection of Sample of Teeth:

A total of one hundred twenty extracted mandibular human teeth, excluding second and third molars, were selected according to predifined standards. Each tooth had to be easily distinguishable. The root surface areas as far as the cemento enamel junction had to be intact. The roots had to have normal shape and form, be complete, and exhibit no evidence of macroscopic pathological changes. No differentiation between right and left teeth was made.

\section{B. Selection of Membrane Materials:}

The material had to have thickness of at least 250 microns after membrane formation and preferably be air cured. It should further remain stable after membrane formation in regard to thickness, shape, dimensional stability, toughness and permit the inclusion of a dye.

Formvar, polyvinyl chloride, polyvinyl alcohol and air cured latex were all tested. Formvar was selected after solutions of different concentrations of each of these materials were tried. A solution of 2.5 grams of Formvar (Polysciences, Inc.) dissolved in 25 milliliters of ethylene dichloride to which 0.4 grams of amacid phloxine 
(a red dye) - (American Aniline Products, Inc.) gave the most optimal result.

\section{Procedure :}

1. Measurement of Total Root Surface Area

The cemento enamel junction of each tooth was marked with a sharp pencil; in doubtful cases, this was accomplished under a disecting microscope. The root was then coated with the Formvar solution (Figures 1 and 2).

The coating was air cured for at least 20 to 30 minutes and the membrane was slit from the cemento enamel junction to the apex and peeled away from the root. The membrane was flattened on a glass slide and a reference metal plate was placed beside the membrane (Figure 3). The metal plate was made by Cameron Instrument Supply Co. and had a known area of 25 square millimeters on the flat side (accuracy \pm 0.0004 square millimeters) (Figures 1 and 3 ).

A picture was taken of the membrane with a $50 \mathrm{~mm}$ auto Micronikkor lens with a $1: 1$ ratio (Figure 4 ). The photographis film was developed and dried by normal means and the pictures were enlarged three times. The photographic image of the membrane, as well as the one of the metal plate was measured with a Keuffer \& Esser compensating polar planimeter number 62000 (Tigure 5).

The actual root surface area was calculated from this formula

$$
\begin{aligned}
& \text { Actual Root } \\
& \text { Surface Area }
\end{aligned}=\frac{\begin{array}{l}
\text { Measured Total } \\
\text { Root Surface Area } \times \text { Actual Area } \\
\text { of Plate }
\end{array}}{\text { Measured Area of Plate }}
$$



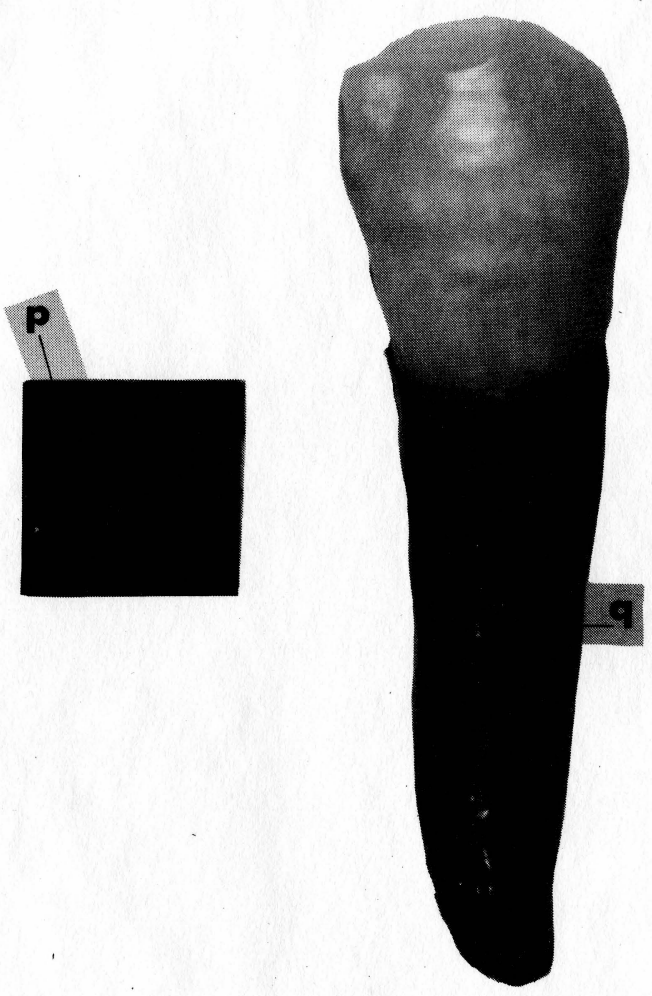

\section{FIGURE I}

TOOTH COATED WITH FORMVAR

MEMBRANE (q) FRONTAL VIEN AND REFERENCE METAL PLATE ( $p$ ) 

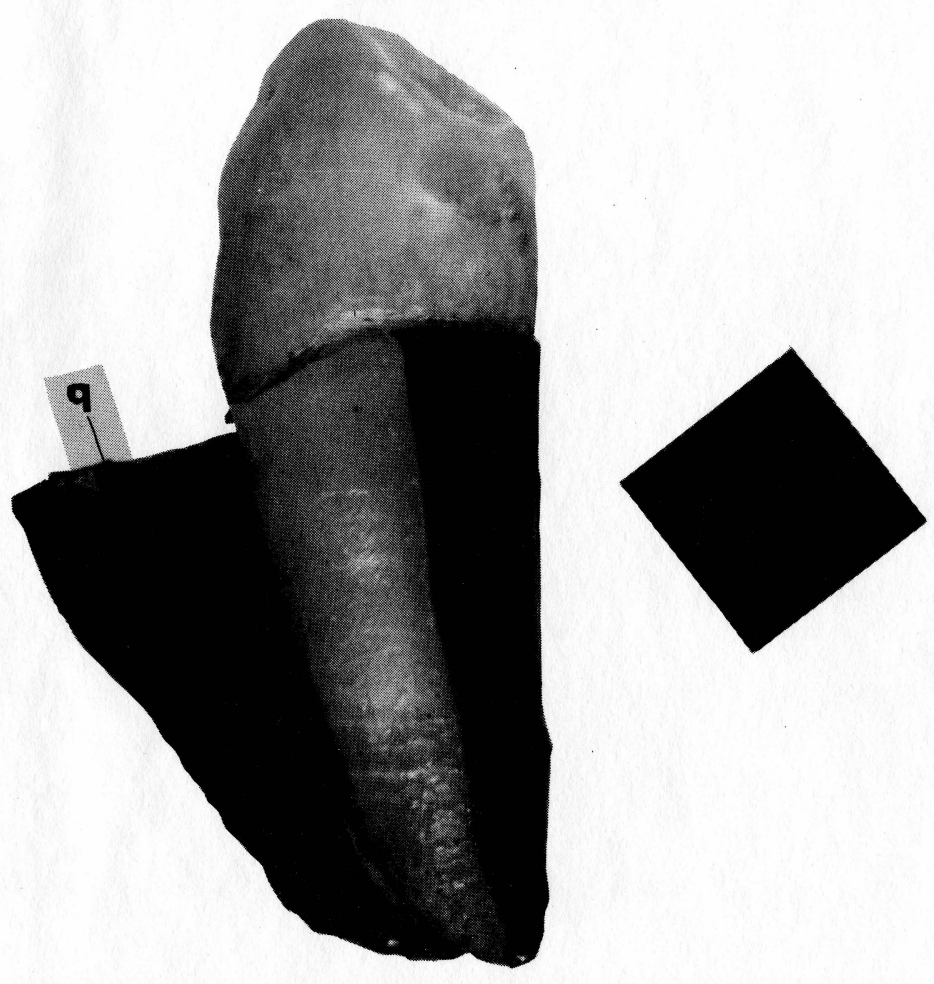

FIGURE 2

MEMBRANE (q) HALF PEELED AWAY

ILATERAL VIEW 


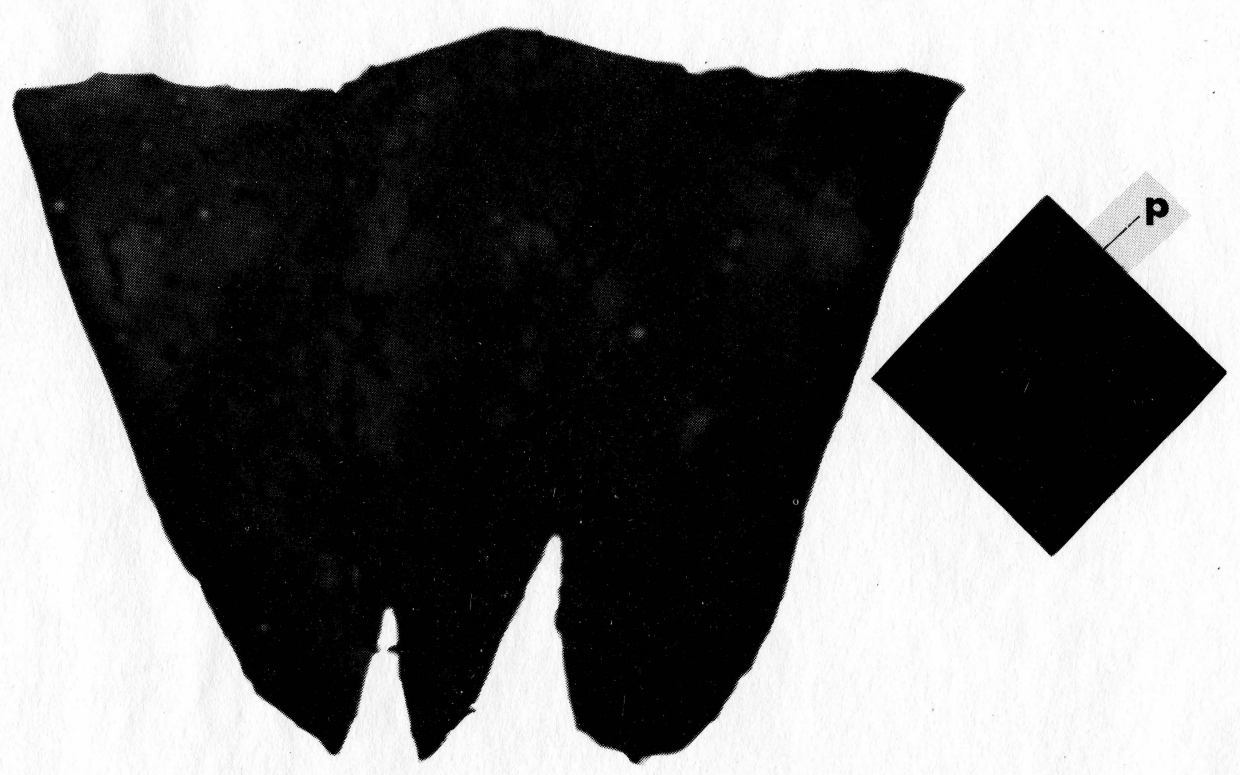

FIGURE 3

FLATTENED MEMBRANE AND REFERENCE PLATE 


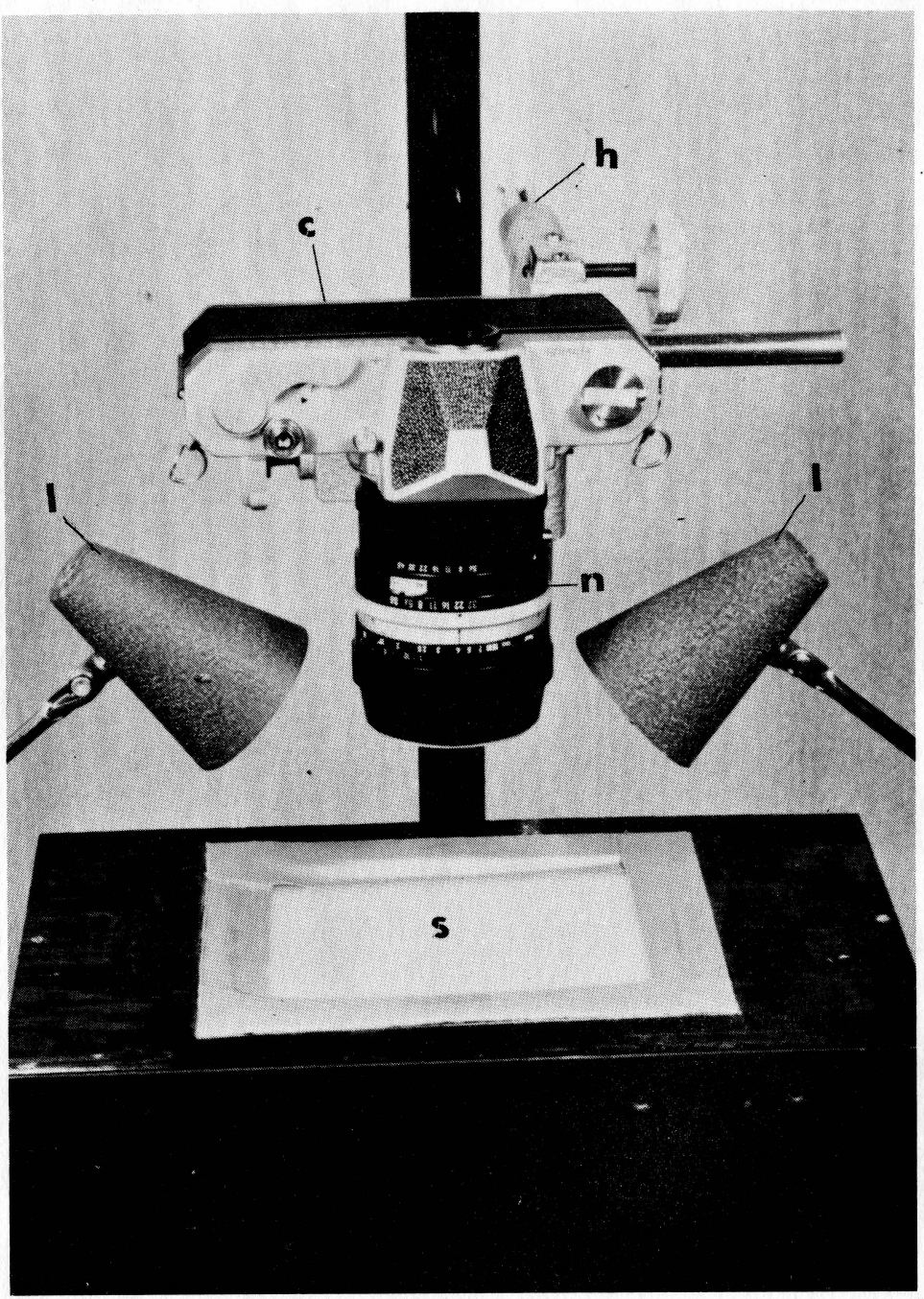

FIGURE 4

PHOTOGRAPHIC SET UP

h- CAMERA HOLDER

c- NIKON CAMERA

n- AUTO MICRONIKKOR LENS

1- LIGHT SOURCES

s- BACKGROUND IIGHT 


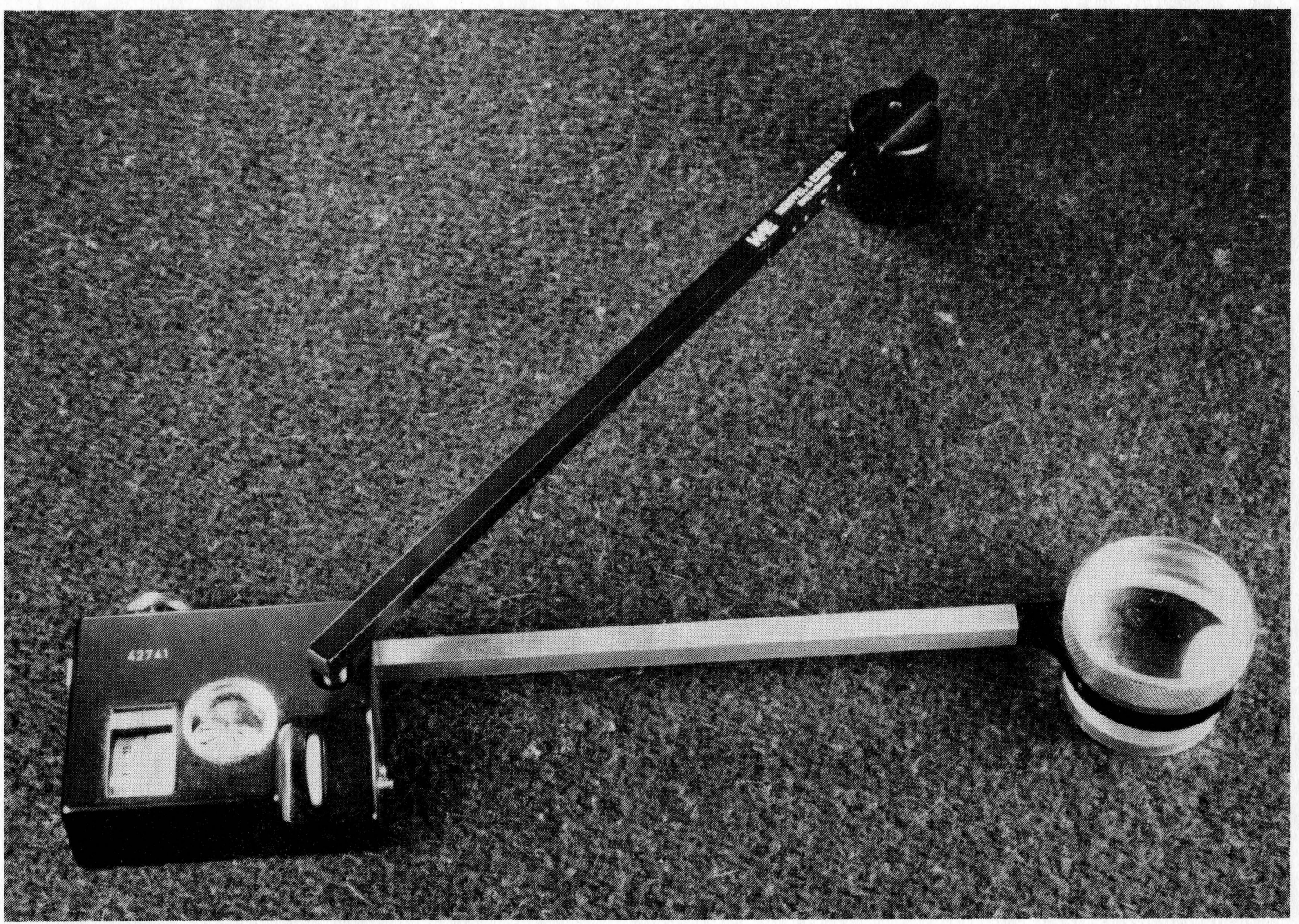

FIGURE 5

COMPENSATING POLAR PLANIMETER 
2. Measurement of Projected Root Surface Area

The projected root surface area was determined for both the MesioDistal and Bucco-Lingual directions for every tooth. The cemento enamel junction was marked with a sharp pencil (Figures 6 and 7). The tooth was positioned with the long axis perpendicular to the photographic film and parallel to the surface on which it was resting. This was checked by the use of Stanley H-1292 level.

The first molars were sectioned occlusally at the bifurcation when the Bucco-Iingual projected root surface area photograph was taken (Figure 8). The two roots were separated and the photograph taken of each root. The Bucco-Lingual projected root surface areas of each root were reasured separately and the measurements added (Figure 9). The actual projected root surface area for each tooth was calculated by the following formula

$$
\begin{aligned}
& \text { Actual Projected } \\
& \text { Root Surface Area }
\end{aligned}=\frac{\begin{array}{l}
\text { Measured Projected } \\
\text { Root Surface Area } x_{\text {of Plate }}
\end{array}}{\text { Measured Area of Plate }}
$$

D. Standarization of Technique and

Testing Precision of Procedure:

Different photographs were taken at varying heights between the camera and the tooth, adjacent to which was a ruler.

The length and width of the tooth in the different photographs were measured and calculated and found to be the same when referred to the ruler in each photograph. For the study, however, the object film distance was maintained constant so far as was possible. 


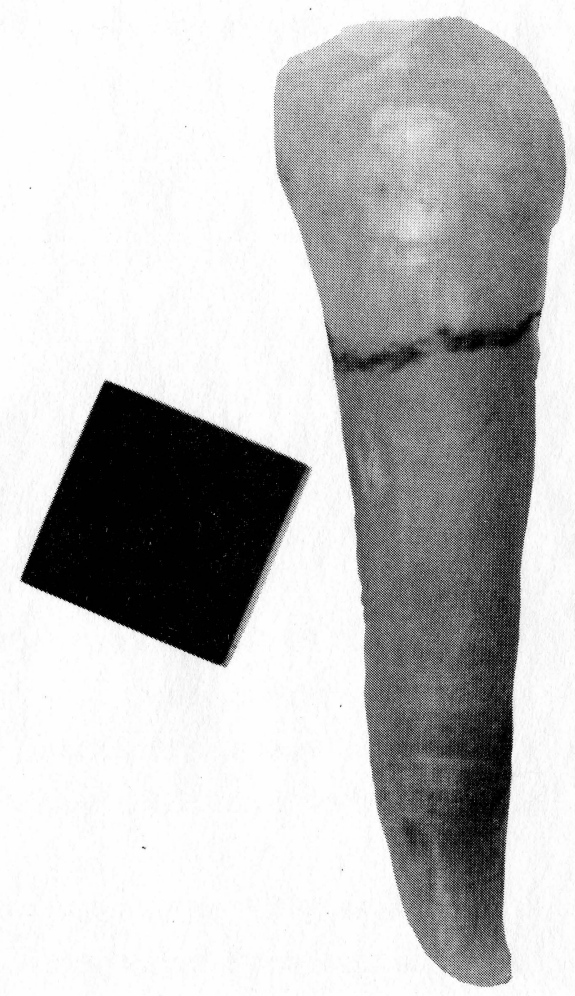

FIGURE 6

MESIO-DISTAL PROJECTED ROOT SURFACE AREA.

OF A MANDIBULAR FIRST PREMOLAR 


$$
1
$$




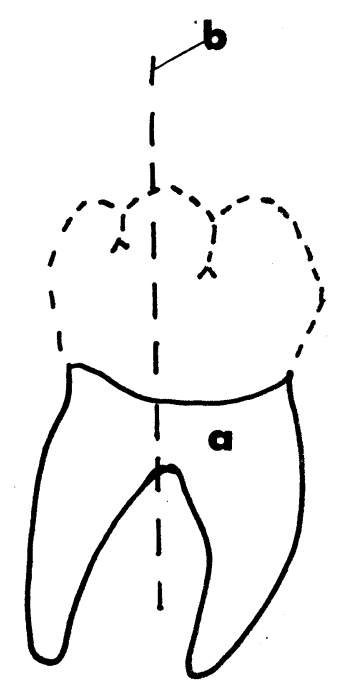

FIGURE 8

MANDIBULAR FIRST PERMANENT MOLAR

2- MESIO DISTAI PROJECTED ROOT SURFACE AREA

b- SECTIONING OF MESIAL AND DISTAL BOOT
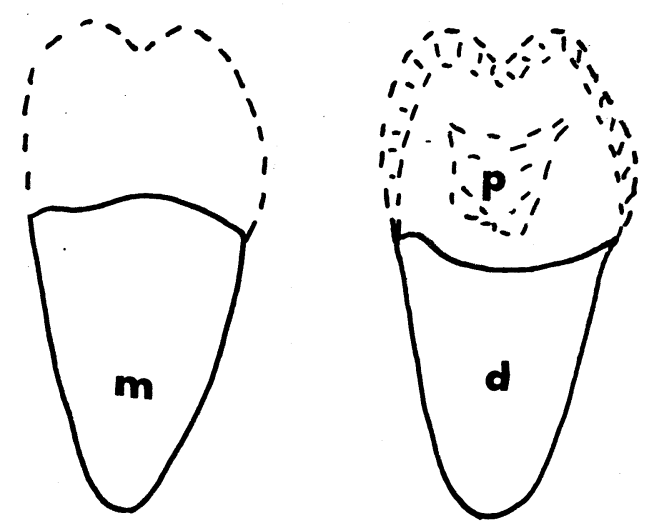

FIGURE 9

BUCCO LINGUAL PROJECTED ROOT SURFACE AREA

m- PROJECTED ROOT AREA OF MESIAL ROOT

d- PROJECTED ROOT AREA OF DISTAL ROOT

p- PULP CHAMBER 
The sides of a standard cylinder 10 millimeters in height and 5 millimeters in diameter were coated with the membrane material, the membrane air cured, slit and flattened. The area was calculated mathematically to be 157 square millimeters ( $(\mathrm{dh})$. The area of the membrane as measured by this technique was found to be 155 square millimeters (Figure 10).

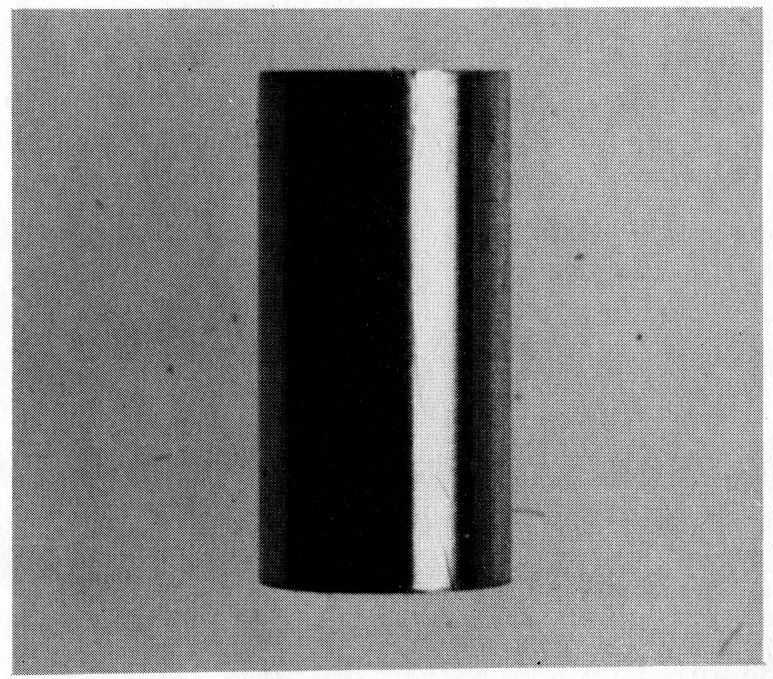

FIGURE 10

CYLINDER USED TO TEST

PRECISION OF PROCEDURE

Photographs were taken of the cylinder and reference plate and measured. The actual "projected" area of the cylinder was calculated mathematically to be 50 square millimeters, while the measured area was found to be 49 square millimeters (Figure 10).

To test the reliability of the method several coatings were applied to the same tooth and the area of each different resulting membrane measured. 
The measurements obtained compared as follows:

$$
\begin{aligned}
& \text { 1. } 124.75 \mathrm{~mm}^{2} \\
& \text { 2. } 126.00 \mathrm{~mm}^{2} \\
& \text { 3. } 125.75 \mathrm{~mm}^{2}
\end{aligned}
$$

To check for shrinkage, a membrane was photographed at ten minute intervals during a 60 minute period and measured. None was found.

A membrane was measured, then cut in two, and then into four sections. Each time a photograph was taken, each piece was measured, and then added to obtain the whole. The messurements obtained were the following

$$
\begin{array}{ll}
\text { 1. whole membrane } & 149.600 \mathrm{~mm}^{2} \\
\text { 2. 2(two halves) } & 146.200 \mathrm{~mm}^{2} \\
\text { 3. } 4(1 / 4 \text { of each membrane) } & 142.76 \mathrm{~mm}^{2}
\end{array}
$$

The reference metal plate was included in every picture and measured everytime. 
CHAPTER IV

FINDINGS

\section{A. Resume of Findings:}

An average of five measurements were done with the compensating polar planimeter of the membrane, projected root surface areas and the plate. The total amount of measurements done was about 3500. For purposes of discussion, reference will be made to Tables I to VI in this chapter.

The projected and the total root surface areas of the measured teeth increased progressively from the central incisors to the first molars except for the canine teeth. The values for the latter were higher than the ones for the second premolars but smaller than the molars.

The mean for the Mesio-Distal projected root area ranged from 33.357 square millimeters for the central incisors to 96.007 square millimeters for the molars, the standard deviation from 4.969 square millimeters to 10.440 square millimeters.

The range of values for the mean of the Bucco-Lingual projected root area was from $63.327 \pm 7.861$ square millimeters (central incisors) to $146.194 \pm 13.760$ square millimeters (first permanent molars).

The ratio obtained by dividing the Mesio-Distal into the BuccoLingual root surface area of each tooth ranged from $1.52 \pm 0.103$ for the 
first molars to $1.96 \pm 0.146$ for the lateral incisors. The best corretion was found between the canines and posterior teeth. Using the ratios obtained for these teeth, either the Bucco-Iingual or Mesio-Distal projected root areas can be found to a fairly accurate degree if one of them is known. Clinically, this has an immense value because it will facilitate the calculation of the effective root pressure if the translatory force is known (page28). When standards have been set for the effective (optimal) root pressure for each tooth then the optimal translatory force can be calculated.

The correlation between the total and Mesio-Distal projected root surface area was the more variant, e. g. Table I, central incisor tooth $1 \mathrm{~T}, 3.67$; tooth $1 \mathrm{~J}, 5.39$.

The best correlation for all of the measured mandibular teeth was found to be the one between the total and the Bucco-Lingual projected root surface area. The ratios ranged from 2.33 for the lateral incisors to 2.75 for the molars; the standard deviation varied from 0.111 for the canines to 0.194 for the first premolars. The ratios ranged from 2.007 (Table IV, tooth 4F) to 2.98 ( Table VI, tooth 6D). 
Tooth Root Surface Areas (Sq. mm)

No.

Projected

IA

32.000

69.250

27.750

58.250

30.500

60.500

33.250

69.250

29.146

51.500

30.750

78.185

33.250

60.000

27.000

55.250

33.008

55.250

35.250

74.422

44.625

69.956

32.579

56.970

33.750

65.909

38.354

65.772

29.000

52.920

40.364

67.909

64.008

33.500

26.500

54.000

36.057

62.499

42.525

74.752

63.327

150.144

1.82

18.433

7.861

Mean

33.357

4.969

Deviation
156.993

Totel

164.750

2.16

2.10

$141.000 \quad 1.98$

$168.220 \quad 2.08$

$124.500 \quad 1.75$

151.182

2.22

1.80

2.05

1.78

2.11

1.57

1.75

1.95

1.71

1.82

1.68

1.91

2.04

1.73

1.76
3.67

2.10

Ratios

$\mathrm{T} / \mathrm{M}-\mathrm{D}$

T/B-L

2.38

2.42

2.33

2.43

2.42

2.22

2.38

2.57

2.43

2.55

2.35

3.69

2.41

4.21

2.37

4.63

2.43

4.16

2.27

4.15

2.63

4.43

2.52

4.82

2.30

4.69

2.30

3.98

4.969

TABLE I 
Tooth Root Surface Areas (Sq. mm)

No. $M-D$ Projectod

$2 \mathrm{~A}$

34.500

64.646

157.589

72.687

64.705

170.571

167.920

64.453

158.948

73.052

178.536

82.000

71.108

72.990

70.707

39.215

34.666

76.250

76.600

39.215

40.205

81.121

66.000

35.000

34.372

62.250

57.142

69.999

65.429

63.476

61.110

73.147

33.258

35.424

66.211

7.495

Standard

Deviation 5.471
$183.607 \quad 1.97$

152.686

156.249

157.784

169.250

175.959

183.750

171.864

151.750

130.521

151.857

142.000

139.795

155.355

165.996

2.12

161.094

1.96

14.454

0.146

0.273

4.41

1.82

4.08

2.00

4.29

1.80

4.02

2.19

4.88

1.95

4.49

2.02

4.57

1.88

4.91

1.81

4.41

2.02

4.62

2.17

4.71

2.19

4.76

2.11

4.64

1.71

4.36

4.99
Ratios

$\mathrm{BL} / \mathrm{K}-\mathrm{D}$

$T / M-D$

$T / B-L$

4.56

2.44

4.79

2.35

4.96

2.59

4.41

2.46

4.44

2.44

2.24

2.24

2.14

2.23

2.22

2.29

2.26

2.60

2.44

2.28

2.17

2.17

2.20

2.54

2.26

TABLE II 
Tooth Root Surface Areas (Sq. mm)

No.

\section{Projected}

B-I

49.057

74.537

72.395

57.575

60.576

62.443

65.529

59.306

66.826

85.576

49.735

64.903

66.345

69.250

67.707

48.500

46.874

64.000

47.250

64.058

73.000

62.045

Standard

Deviation
11.494

104.628

80.555

105.146

113.000

113.323

91.281

117.823

125.000

82.518

99.019

108.172

116.835

89.898

76.041

92.186

93.876

81.852

104.160

109.270

98.956

15.012
Totel

186.500

242.000

206.600

235.538

259.000

269.333

234.360

267.500

287.500

205.000

239.210

249.067

272.303

221.568

188.250

199.998

234.984

187.750

246.930

255.000

234.419

30.474

0.158

1.52

1.44

1.39

1.73

1.81

1.73

1.54

1.76

1.46

1.66

1.52

1.63

1.69 .

1.33

1.57

1.97

1.47

1.73

1.63

1.50

1.60
Ratios

BL/M-D

3.75

3.93

3.27

3.88

4.27

2.17

3.67

2.50

3.97

2.29

3.85

2.37

3.49

2.33

2.50

2.31

2.56

2.24

2.29

2.37

2.57

2.27

2.30

2.48

2.41

2.30

2.33

2.46

2.47

$T / B-I$ 
Tooth Root Surface Areas (Sq. mn)

No. $M-D$ Projected

Total
43.008

51.819

63.537

65.621

65.305

59.183

45.000

43.747

59.500

40.000

47.367

42.705

49.256

47.958

55.445

51.960

54.807

43.268

52.000

48.108

73.402

83.500

83.000

78.000

83.080

74.099

79.000

80.302

73.200

166.666

1.71

$162.032 \quad 1.45$

214.421

1.31

$215.142 \quad 1.37$

194.439

1.36

$211.536 \quad 1.73$

164.421

1.51

163.500

1.39

$206.938 \quad 1.57$

173.166

1.81

184.000

1.61

173.000

1.54

$206.817 \quad 1.58$

192.200

1.63

$220.364 \quad 1.70$

$209.500 \quad 1.60$

206.500

1.35

$178.000 \quad 1.54$

187.000

1.54

$196.000 \quad 1.52$

79.721

187.363

1.54

20.502

0.138

0.147

0.194

Ratios

$T / M-D$

$T / B-L$

3.87

2.27

3.13

2.16

3.37

2.57

3.28

2.39

2.98

2.20

2.57

2.07

3.65

2.42

3.74

2.69

3.48

2.21

4.33

2.39

3.88

2.42

4.27

2.63

4.20

2.49

4.01

2.46

3.97

2.33

4.63

2.52

3.77

2.79

4.11

2.25

3.60

2.33

4.07

2.68

Standard

Deviation

10.346 


\begin{tabular}{|c|c|c|c|c|c|c|}
\hline $\begin{array}{l}\text { Tooth } \\
\text { No. }\end{array}$ & $\begin{array}{l}\text { Root Su } \\
\text { Pro } \\
\end{array}$ & $\begin{array}{l}\text { ce Areas } \\
\text { eted } \\
\text { B-I }\end{array}$ & $\begin{array}{r}\text { Sq. } \mathrm{mm}) \\
\text { Total } \\
\end{array}$ & $B L / M-D$ & $\begin{array}{l}\text { Ratios } \\
T / M-D\end{array}$ & $T / B-L$ \\
\hline $5 \mathrm{~A}$ & 49.666 & 80.611 & 199.998 & 1.62 & 4.03 & 2.11 \\
\hline $5 B$ & 48.039 & 76.000 & 180.353 & 1.58 & 3.75 & 2.37 \\
\hline $5 C$ & 54.566 & 91.088 & 227.450 & 1.67 & 4.17 & 2.49 \\
\hline $5 D$ & 45.913 & 78.431 & 190.344 & 1.71 & 4.15 & 2.43 \\
\hline $5 E$ & 58.823 & 91.000 & 228.603 & 1.55 & 3.89 & 2.51 \\
\hline $5 F$ & 49.994 & 65.345 & 180.000 & 1.30 & 3.60 & 2.75 \\
\hline $5 G$ & 53.845 & 82.691 & 203.844 & 1.54 & 3.78 & 2.46 \\
\hline $5 \mathrm{H}$ & 56.249 & 83.172 & 216.666 & 1.48 & 3.85 & 2.60 \\
\hline $5 I$ & 52.884 & 77.450 & 200.959 & 1.46 & 3.80 & 2.59 \\
\hline $5 \mathrm{~J}$ & 55.637 & 84.614 & 203.800 & 1.52 & 3.66 & 2.41 \\
\hline $5 K$ & 44.230 & 73.500 & 174.998 & 1.66 & 3.96 & 2.38 \\
\hline $5 \mathrm{~L}$ & 52.163 & 79.702 & 198.075 & 1.53 & 3.80 & 2.50 \\
\hline $5 \mathrm{M}$ & 55.768 & 83.010 & 208.267 & 1.49 & 3.73 & 2.51 \\
\hline $5 \mathrm{~N}$ & 50.961 & 73.653 & 191.000 & 1.44 & 3.75 & 2.59 \\
\hline 50 & 52.550 & 73.250 & 204.901 & 1.39 & 3.90 & 2.80 \\
\hline $5 P$ & 58.088 & 88.137 & 229.750 & 1.52 & 3.96 & 2.61 \\
\hline $5 Q$ & 47.794 & 68.250 & 177.000 & 1.43 & 3.70 & 2.59 \\
\hline $5 R$ & 57.450 & 74.999 & 189.421 & 1.31 & 3.30 & 2.53 \\
\hline 55 & 54.281 & 77.941 & 184.068 & 1.44 & 3.39 & 2.36 \\
\hline $5 \mathrm{~T}$ & 47.100 & 85.000 & 199.000 & 1.80 & 4.22 & 2.34 \\
\hline $\begin{array}{l}\text { Mean } \\
\text { Standard }\end{array}$ & 52.300 & 79.392 & 199.424 & 1.52 & 3.82 & 2.50 \\
\hline Deviation & 4.282 & 6.928 & $\begin{array}{l}16.756 \\
\text { TABLE V }\end{array}$ & 0.127 & 0.278 & 0.153 \\
\hline
\end{tabular}


Tooth Root Surface Areas (Sq. mm)

No.

Projected

Totel

Ratios

\begin{tabular}{|c|c|c|c|c|c|c|}
\hline & $M=D$ & $B-L$ & Totel & $\mathrm{BL} / \mathrm{N}-\mathrm{D}$ & $T / M-D$ & $T / B-L$ \\
\hline $6 A$ & 109.000 & 156.000 & 427.000 & 1.43 & 3.92 & 2.74 \\
\hline $6 B$ & 82.987 & 129.560 & 377.024 & 1.56 & 4.54 & 2.91 \\
\hline $6 c$ & 95.600 & 143.373 & 385.000 & 1.50 & 4.03 & 2.69 \\
\hline $6 D$ & 109.854 & 158.303 & 472.324 & 1.44 & 4.30 & 2.98 \\
\hline $6 E$ & 96.038 & 161.000 & 420.750 & 1.68 & 4.38 & 2.61 \\
\hline $6 F$ & 110.000 & 156.345 & 428.000 & 1.42 & 3.89 & 2.74 \\
\hline $6 G$ & 94.500 & 131.597 & 378.000 & 1.39 & 4.00 & 2.87 \\
\hline $6 \mathrm{H}$ & 89.898 & 143.662 & 383.733 & 1.60 & 4.27 & 2.67 \\
\hline $6 I$ & 105.250 & 168.013 & 429.410 & 1.60 & 4.08 & 2.56 \\
\hline $6 \mathrm{~J}$ & 106.060 & 147.500 & 433.225 & 1.39 & 4.08 & 2.94 \\
\hline $6 \mathrm{~K}$ & 84.600 & 141.845 & 360.988 & 1.68 & 4.20 & 2.55 \\
\hline 6L & 101.556 & 157.648 & 440.000 & 1.55 & 4.33 & 2.79 \\
\hline $6 M$ & 79.806 & 122.705 & 352.000 & 1.54 & 4.41 & 2.87 \\
\hline $6 \mathrm{~N}$ & 94.000 & 144.793 & 400.425 & 1.54 & 4.26 & 2.77 \\
\hline 60 & 77.250 & 117.845 & 338.807 & 1.53 & 4.39 & 2.87 \\
\hline $6 P$ & 86.452 & 145.514 & 381.648 & 1.68 & 4.41 & 2.62 \\
\hline $6 Q$ & 110.409 & 135.750 & 394.606 & 1.23 & 3.57 & 2.91 \\
\hline $6 R$ & 100.933 & 155.230 & 413.750 & 1.54 & 4.10 & 2.67 \\
\hline $6 s$ & 93.268 & 142.520 & 392.943 & 1.53 & 4.19 & 2.76 \\
\hline $6 T$ & 92.787 & 164.682 & 438.773 & 1.77 & 4.73 & 2.66 \\
\hline Mean & 96.007 & 146.194 & 402.420 & 1.52 & 4.20 & 2.75 \\
\hline $\begin{array}{l}\text { Standard } \\
\text { Deviation }\end{array}$ & 10.440 & 13.760 & 32.456 & 0.103 & 0.305 & 0.130 \\
\hline
\end{tabular}




\section{CHAPTER V}

\section{DISCUSSION}

The stresses developed within the periodontal ligament are dependent upon the intensity and the type of force system applied to the crown of the tooth. Essentially there are three types of stresses present: (1) Compressive stresses on the side of the root where the periodontal ligament is compressed; (2) tensile stresses on the tension side where the periodontal fibers are being stretched; (3) shearing stresses around the edges of the root and in the regions between areas of compression and tension. These stresses cannot readily be separated and measured. In a quantitative evaluation made by Jarabak and Fizzell (1963) these stresses were expressed as "pressure" in grams per square millimeter of projected root surface area.

This pressure is the important factor in determining tooth movement and not the force applied to the crown of the tooth.

Effective root surface area can be defined as that portion of the total root surface area of the root of a tooth that is involved directly in resisting the movement of the tooth in a specific direction. This takes into consideration the convexities of the tooth root surface in the vertical and horizontal planes.

Jarabak and Fizzell assumed that the projected root surface area 
was a close approximation of the effective root area and thus simplified their study of the phenomenon of tooth movement.

The reader must always bear in mind that the effective root surface area is a tri-dimensional entity (due to the convexities of the tooth), whils the projected root surface area is bi-dimensional, hence, the effective root surface area is always larger than the projected. Projected root surface area can be defined as the image or shadow of the root of a tooth created in a film, the latter being parallel to the long axis of the tooth.

From now to facilitate this discussion the projected root surface area and the effective root surface area will be considered approximately equal in size.

When a force is applied to a tooth, a portion of the total root surface area will resist directly the movement, (effective root area). When translation occurs and the tooth is in equilibrium, the summation of all the resisting forces may be considered as if it were a single force, $F_{r}$, applied at the centroid of the projected root surface area and equal and opposite to $F_{m}$ (acting force). Under these conditions, a simple relation exists between the translating force and the stresses on the root in grams per unit area.

For purposes of this discussion, the teeth used in the study will be referred to in the following manner central incisors $\left(I_{1}\right)$, lateral incisors $\left(I_{2}\right)$, canines $(C)$, first premolars $\left(P_{1}\right)$, second pre- 
molars $\left(P_{2}\right)$, and first molars $\left(K_{4}\right)$. The uniform stresses over the area of the root can be expressed as

$$
S=\frac{F_{m}}{A_{r}}
$$

where $S$ is the stress on the root surface, $F_{m}$ is the translating force and $A_{r}$ is the projected root surface area (effective root surface area). Sine these stresses cannot be separated and measured they are collectively expressed as "effective" root pressure.

If the net translatory force in the distal direction to a mandibular canine is 100 grams and the Bucco-Lingual projected root surface area is 98 square millimeters, the stress in this case is $\frac{100}{98}=1.0204$ grams per square millimeter anywhere in the projected root surface area. The effective root pressure thus can be defined as the ratio of the net force on a tooth divided by the projected (effective) root surface area perpendicular to the force or as the required pressure needed to start the tooth moving.

In this experiment, values have been determined for the first time of projected root surface areas both in the Bucco-Lingual as well as Mesio-Distal directions. Having set these standards, effective root pressure can be calculated by dividing the net translatory force by the projected root surface area of the specific tooth.

The mean of the projected root surface areas of the mandibular teeth are presented in table VII. 
TABLE VII

Projected Root Surface Areas

\begin{tabular}{lcc|cc} 
& Mean & $\begin{array}{c}\text { Mesio-Distal } \\
\text { Standard } \\
\text { Deviation }\end{array}$ & Mean & $\begin{array}{c}\text { Bucco-Lingual } \\
\text { Standard } \\
\text { Deviation }\end{array}$ \\
\hline$I_{1}$ & 33.357 & 4.969 & 63.327 & 7.861 \\
$I_{2}$ & 35.424 & 5.471 & 66.211 & 7.495 \\
$\mathrm{C}$ & 62.045 & 11.494 & 98.956 & 15.012 \\
$\mathrm{P}_{1}$ & 51.479 & 7.689 & 79.721 & 10.346 \\
$\mathrm{P}_{2}$ & 52.300 & 4.282 & 79.392 & 6.928 \\
$\mathrm{M}_{1}$ & 96.007 & 10.440 & 146.194 & 13.760 \\
\hline
\end{tabular}

Total root surface area was also measured by using a membrane technique. Standards were set for the teeth in the mandibular arch. The measurement of total root surface area has been reported by some investigators in the past, of which Jepsen, Boyd, and Tylman and Tylman had results most in agroement with this study.

The results of this work are presented in comparison with these

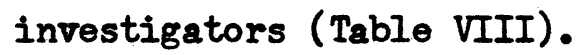

The technique employed here was similar to Jepsen, except for details of photography and the inclusion of a known area (metal plate) in every picture to facilitate and standarize the calculation of the total root surface area.

The smaller standard deviations obtained in this work advocate that this technique was probably more precise.

The hypothesis can be made that there is a definite relationship 
between projected and total root surface area, and between the projected areas themselves for each speciflc tooth. These ratios are summarized in table IX.

TABLE VIII

Total Root Surfece Areas ( $\mathrm{Sg}, \mathrm{mm})$

\begin{tabular}{lll|ll|l|l} 
Teeth & $\begin{array}{l}\text { Present Study 1967 } \\
\text { Average } \\
\text { Area }\end{array}$ & $\begin{array}{l}\text { Standard } \\
\text { Deviation }\end{array}$ & $\begin{array}{l}\text { Jepsen } \\
\text { Arerage } \\
\text { Area }\end{array}$ & $\begin{array}{l}1963 \\
\text { Standard } \\
\text { Deviation }\end{array}$ & $\begin{array}{l}\text { Tylman } \\
\text { and } \\
\text { Tylman } \\
1960\end{array}$ & $\begin{array}{l}\text { Boyd } \\
1958\end{array}$ \\
\hline $\mathrm{I}_{1}$ & 150.44 & 18.433 & 154.0 & 26.5 & 103.0 & 162.2 \\
$\mathrm{I}_{2}$ & 161.094 & 14.454 & 168.0 & 21.5 & 124.0 & 174.8 \\
$\mathrm{C}$ & 234.419 & 30.474 & 268.0 & 42.2 & 159.0 & 272.2 \\
$\mathrm{P}_{1}$ & 187.363 & 20.502 & 180.0 & 27.2 & 130.0 & 196.9 \\
$\mathrm{P}_{2}$ & 199.424 & 16.756 & 207.0 & 26.6 & 135.0 & 204.3 \\
$\mathrm{M}_{1}$ & 402.420 & 32.456 & 431.0 & 59.5 & 352.0 & 450.3 \\
\hline
\end{tabular}

TABLE IX

Ratios

\begin{tabular}{|c|c|c|c|c|c|}
\hline \multicolumn{2}{|c|}{$\mathrm{BL} / \mathrm{M}-\mathrm{D}$} & \multicolumn{2}{|c|}{$T / M-D$} & \multicolumn{2}{|c|}{ T/B-L } \\
\hline Mean & $\begin{array}{l}\text { Standard } \\
\text { Deviation }\end{array}$ & Mean & $\begin{array}{l}\text { Standard } \\
\text { Deviation }\end{array}$ & Mean & $\begin{array}{l}\text { Standard } \\
\text { Deviation }\end{array}$ \\
\hline 1.82 & 0.202 & 4.54 & 0.505 & 2.39 & 0.123 \\
\hline 1.96 & 0.146 & 4.56 & 0.273 & 2.33 & 0.144 \\
\hline 1.60 & 0.158 & 3.80 & 0.282 & 2.38 & 0.111 \\
\hline 1.54 & 0.138 & 3.71 & 0.147 & 2.41 & 0.194 \\
\hline 1.52 & 0.127 & 3.82 & 0.278 & 2.50 & 0.153 \\
\hline 1.52 & 0.103 & 4.20 & 0.305 & 2.75 & 0.130 \\
\hline
\end{tabular}




\section{CHAPTER VI \\ SUMMARY AID CONCLUSSIONS}

\section{A. Summary:}

The surface area of the root of each tooth differs. Equal forces applied to teeth with different size roots are not distributed equally to the wall of the alveoli. When the forces applied to the crowns are identical but the root surface areas are different, the tooth with greater root surface area will exert less pressure against the wall of its alveolus through the periodontal ligament. On the other hand the tooth with lesser root surface area will develop greater pressure against the socket wall.

It is logical to conclude that tooth movement is the result of pressure against the alveolar wall. This results in bone resorption through osteoclastic activity. Orthodontic forces applied to the crowns of the teeth are distributed to the roots where they are resisted.

The values of these pressures can be calculated by dividing the sum of the forces acting on a tooth by the value of the effective root surface area that lies perpendicular to the translatory force. This can be done for the specific tooth using the standards set forth in this experiment. 
In this exporiment an accurate mothod has been devised to mea- ... sure the total and effective (projected) root surface areas of teeth. The precision of the method is evidenced by the lower standard deviations obtained for the total root surface areas of this study than that of other investigators (Table VIII).

Standards for total and projoctod root surface areas were establishod. This will facilitate the calcelation of effective root pressure for the teeth in the mandibalar arch.

A constant ratio was found to exist between total root surface area and the Bucco-Iingual effective root surface area (Table IX).

TABLE X

$$
\text { T/B-I }
$$

$\begin{array}{ll}\mathrm{I}_{1} & 2.39 \\ \mathrm{I}_{2} & 2.33 \\ \mathrm{C} & 2.38 \\ \mathrm{P}_{1} & 2.41 \\ \mathrm{P}_{2} & 2.50 \\ \mathrm{M}_{1} & 2.75\end{array}$

Total root surface area can be calculated if the Bucco-Lingual effective root surface area is known or viceversa. B. Conclusions:

1. This study provided an accurate method of measuring total and effective root surface area. 
2. Standards were set for the first time for effective root surface area for all mandibular human toeth except for the second and third molars. These values will help in determining effective root pressure.

3. Total root surface areas were moasured and compared to the values obtained by other investigators. The method employed was felt to be quite reliable since the standard deviation values for each tooth is smaller than that reported by any other investigator.

4. A very significant correlation was found between the total root surface area and the Bucco-lingual offective (projected) root surface area (Tables IX and X). By using the ratio between these areas, one of these two root surface areas can be determined if the other is known.

5. A significant correlation was found between the two projected root surface areas (BL/K-D - Table IX) of the canines and posterior teeth. This relationship did not hold for the incisor teoth.

6. Also, a less significant correlation was found between the total root surface area and the Mesio-Distal (projected) root surface area.

7. A more accurate anchorage values determination can be calculated with the effective root surface areas standards established in this investigation.

8. The method designed for this experiment, the values obtained for projected root surface areas, the total root surface areas as well as the ratios obtained between them are worthy of consideration for future studies. 


\section{BIBLIOGRAPHY}

Brown, R. A method of measurement of root area. Journal of the Canadian Dental Assn., 1950.

Boyd, J. I. A preliminary investigation of the support of partial dentures and its relationship to vertical loads. The Dental Practitioner, $9: 2,1958$.

Burstone, C. J. The biomechanics of tooth movement. Vistas in orthodontics. Lea and Febiger, Philadelphia, 1962.

Freeman, C. Root surface area related to anchorage in the Begg technique; M. S. Thesis, University of Tennessee, 1965.

Geigel, C. F. A qualitative study of the biophysics of tooth movement by means of a three dimensional analog; M. S. Thesis, Loyola University School of Dentistry, Chicago, 1965.

Hanau, R. L. Orthodontic Mechanics: Dental Engineering. International Journal of Orthodontia, 3:410, 1917.

Jarabak, J. R. and Fizzell, J. A. Technique and Treatment with the ight Wire Appliance. C. V. Mosby Company, St. Louis, 1963.

Jepsen, A. Root surface measurement and method for X-Ray determination of root surface area. Acta Odontologica Scandinavica, 21:35, 1963.

Knudsen, P. A. Ventriklernes Stфrrelsesforhold i Anatomisk Normale Hjerner fra Voksne Mennesker; Thesis, Copenhagen, 1958.

MacEwan, D. C. Treatment of a typical distocclusion case. American Journal of Orthodontics, $40: 350,1954$.

Renfroe, E. W. The Sources of Power. The Bulletin of the National Dental Association, 16:16, 1951.

Storey, E. and Smith, R. Force in orthodontics and its relation to tooth movement. The Australian Journal of Dentistry, 56:11, 1952. 
Tylman, S. D. and S. G. Tylman Thoory and Practice of Crown and Bridge Prosthodontics, C. V. Mosby Company, St. Louls, 1960.

Whoeler, R. C. Textbook of Dental Anatomy and Physiology, W. B. Sandors, 1958. 


\section{APPROVAL SHEET}

The thesis submitted by Juan R. Emmanuell1, Jr. has been read and approved by the director of the thesis. Furthermore, the final coples have been examined by the director and the signature which appears below verifies the fact that any necessary changes have been incorporated, and that the thesis is now given final approval with reference to content and form.

The thesis is therefore accepted in partial fulfillment of the requirements for the degree of Master of Science.

$\frac{\text { May } 5,1967}{\text { Date }}$

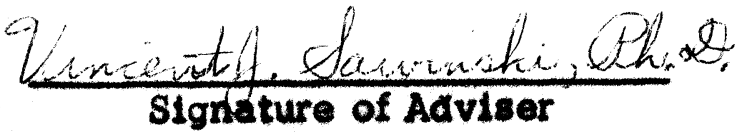

